\title{
The Effectiveness of Tai Chi Exercises on Older Adults in Reducing Fear of Falling: An Evidence- Based Review
}

\author{
Hassan Izzeddin Sarsak* \\ Department of Occupational Therapy, School of Rehabilitation Sciences, University of Jordan, Jordan \\ *Corresponding author: Hassan Izzeddin Sarsak (PhD, OT), Department of Occupational Therapy, Batterjee Medical College, Jeddah, Saudi Arabia
}

Submission: 睯 October 10, 2018; Published: 眥 October 29, 2018

\begin{abstract}
Objectives: this study was conducted to examine and review the evidence available regarding the effectiveness of Tai Chi exercises in reducing the fear of falling in older adults.

Results: our review revealed four studies suggesting that in older adults with a fear of falling, the Tai Chi program compared to no or alternative traditional educational program may produce a greater significant reduction in fear of falling.
\end{abstract}

Conclusion: Tai Chi exercises are effective and reduce the fear of falling in older adults significantly.

Keywords: Tai Chi; exercise; Education program; Older adults; Fear of falling

\section{Introduction}

Fear is an intellectual appraisal of threatening stimuli. Fear usually is considered a normal reaction to a realistic danger or threat to biological integrity or self-concept, but it is not normal to experience an overwhelming and prolonged state of fear. Human studies verify that fear circuitry is located in the amygdala. Sensory information is sent to the amygdala where it is projected to the hypothalamus, which in turn activates the sympathetic nervous system. It is the hypothalamic pituitary adrenocortical (HPA) axis that activates a defensive response when experiencing fear. Dysregulation of the HPA axis and structural changes in the hippocampus are associated with signs of fear and stress related disorders. When a person experiences extreme fear, the hormone cortisol is released from the adrenal gland above the kidney. Its job is to prepare the body for fight or flight. Elevated cortisol levels suppress the immune system and are associated with extreme fear and anxiety disorders. Fear of falling has been identified as a common psychological factor. Fear of falling could happen to people without any fall experiences [1]. Fear of falling could be increased with age, can lead to self-imposed activity restrictions (functional decline, decreased mobility, decreased social activity, depression, and low life satisfaction) (Myers, Fletcher, Myers, and Sherk, 1998). Tai Chi is widely used and is one of the best activities recommended to help decrease the effects of muscular rigidity through providing slow stretching movements [2]. The purpose of this study was to examine the evidence of Tai Chi exercises in reducing the amount of fear of falling in older adults. For the purpose of this study, we created a clinical/research PICO question (Population, Intervention, Comparison, and Outcome), a key to evidence-based decision [3]. The PICO formed for our study is as follows:

(P) In older adults with fear of falling

(I) Does a five-week Tai Chi program

(C) Compare to no/ alternative program

(O) Produce a greater reduction of fear of falling.

Methods

\section{Review of literature and search strategy}

A research has been made in the following databases: Ovid (MEDLINE, PsychINFO, and Global Health), and CINAHL. Keywords and Search items used to search articles for our study were Tai Chi, exercise, education program, older adults, geriatrics, and fear of falling. By combining the search results, we found articles on Tai Chi that discuss the relationship between Tai Chi and fear of falling among older adults. Based on the format of PICO question, four most relevant articles were selected for our study. Studies cited in the reference of the four articles along with other articles were also used to collect important information. After all, the strongest evidence-based article was chosen based on level of evidence and significance level to highlight and confirm our results and conclusions. 


\section{Results}

Table 1: A summary of reviewed articles in relation to our PICO.

\begin{tabular}{|c|c|c|}
\hline Article & Our PICO & Relate to PICO (Article Summary) \\
\hline \multirow{3}{*}{ Sattin et al. } & \multirow{2}{*}{$\begin{array}{l}\text { P- In older adults with fear of } \\
\text { falling }\end{array}$} & P- Age: $\geqq 70$ with fall experience \\
\hline & & I- Tai Chi Group (TC) over 12 months \\
\hline & $\begin{array}{l}\text { I- Does a } 5 \text { week+ Tai chi } \\
\text { program }\end{array}$ & C- Wellness Education Group (WE) over 12 months \\
\hline [6] & $\begin{array}{l}\text { C- Compared to no/alternative } \\
\text { program }\end{array}$ & O- Fear of falling reduced significantly in TC. \\
\hline \multirow{4}{*}{ Li et al. [5] } & $\begin{array}{l}\text { 0- Produce a greater reduction } \\
\text { in fear of falling. }\end{array}$ & P- Age: $\geqq 70$ \\
\hline & & I- Tai Chi group (TC) over 6 months \\
\hline & & C- Stretching control group \\
\hline & & $\begin{array}{l}\text { 0- Fear of falling reduced significantly in the TC group compared to stretching control group and the } \\
\text { effects of Tai Chi exercises kept maintaining over 6-month follow-up. }\end{array}$ \\
\hline \multirow{4}{*}{ Wolf et al. } & & P- Age: $\geqq 70$ \\
\hline & & I- Tai Chi Exercises Group (TC) over 15weeks \\
\hline & & C- Computerized Balance Training Group (BT) and Education Group (ED) over 15weeks \\
\hline & & O- Fear of falling reduced significantly in TC compared to BT and ED. \\
\hline \multirow{4}{*}{$\begin{array}{l}\text { Zhang et al. } \\
\text { [2] }\end{array}$} & & P- Age: $\geqq 60$ \\
\hline & & I- Tai Chi Chuan exercise group (TC) over 8 weeks \\
\hline & & C- Control group \\
\hline & & O- Fear of falling reduced significantly in TC compared to control group. \\
\hline
\end{tabular}

The four selected articles were related to the effectiveness of Tai Chi in reduction of fear of falling among older adults. All articles were related to our PICO question. A summary of the four articles in relation to our PICO is as follows (Table 1). Articles are presented based on treatment period.

\section{Discussion}

Zhang et al. [2] which examined the effects of Tai Chi Chuan on physiological function and fear of falling in the less robust elderly was selected as the strongest evidence-based article. Their target

Table 2: A summary of recommendations, plan, and audit tool. population was less robust elderly who are 70-year-old and older, with ambulatory ability, and live in unsupervised environment. Based on the hierarchy of levels of evidence in evidence-based practice, this study was a level II (Evidence obtained from at least one well designed RCT) [4-7]. Level of significance after 8 weeks at the Tai Chi Chuan exercise group as a result of performing 24 simplified forms of Tai Chi exercise was $\mathrm{P}=.006$. Thus, clinical guidelines, recommendations, a plan and audit tool have been developed in our study to implement Tai Chi in clinical settings (Table 2).

\begin{tabular}{|c|c|c|c|c|}
\hline Recommendation & Implementation Plan & Criteria & Audit Method & Compliance Plan \\
\hline $\begin{array}{l}\text { Two therapists will attend } \\
\text { Tai Chi exercise training. }\end{array}$ & $\begin{array}{c}\text { Schedule two therapists } \\
\text { to attend Tai Chi exercise } \\
\text { training. }\end{array}$ & $\begin{array}{c}\text { The two therapists will } \\
\text { attend Tai Chi exercise } \\
\text { training within } 3 \\
\text { months. }\end{array}$ & $\begin{array}{l}\text { The personnel files will } \\
\text { include a certificate of } \\
\text { attendance. }\end{array}$ & $\begin{array}{l}\text { If therapists have not attended the } \\
\text { program in } 3 \text { months, a note will be } \\
\text { filed in their personnel file. }\end{array}$ \\
\hline $\begin{array}{l}\text { The two therapists will } \\
\text { make a Tai Chi exercise } \\
\text { video. }\end{array}$ & $\begin{array}{l}\text { The two therapists will } \\
\text { perform Tai Chi exercises } \\
\text { with separated movements } \\
\text { and continued movements } \\
\text { in the video. }\end{array}$ & $\begin{array}{l}\text { Video will be complet- } \\
\text { ed in } 1 \text { month after } \\
\text { they finish training. }\end{array}$ & $\begin{array}{l}\text { The video will be avail- } \\
\text { able in the OT office. }\end{array}$ & $\begin{array}{l}\text { If the video is not completed in } 30 \\
\text { days, a note of correction will be } \\
\text { placed in the employee's file. }\end{array}$ \\
\hline $\begin{array}{l}\text { A home Tai Chi exercise } \\
\text { program will be developed } \\
\text { by the two therapists. }\end{array}$ & $\begin{array}{l}\text { Lesser forms of Tai Chi exer- } \\
\text { cises will be developed. }\end{array}$ & $\begin{array}{l}\text { Tai Chi exercises home } \\
\text { program will be devel- } \\
\text { oped in } 1 \text { month. }\end{array}$ & $\begin{array}{l}\text { The home exercise pro- } \\
\text { gram will be printed and } \\
\text { available in the OT office. }\end{array}$ & $\begin{array}{l}\text { If the program is not completed a } \\
\text { note of correction will be place in } \\
\text { the employee's file. }\end{array}$ \\
\hline
\end{tabular}


The two therapists will teach other staff members how to perform Tai Chi exercise.
Staff members will attend Tai Chi exercise classes in groups of 5 (or more). New employees can be in oneon-one sessions.
$100 \%$ of existing employees will learn Tai Chi Exercises within 2 months. $100 \%$ of new employees will learn TC exercises in 2 months of arrival.
All staff will report date and time to department supervisor and department supervisor will record it in Tai Chi binder.
Non-compliant staff will meet with department supervisor

\section{Conclusion}

Our review confirmed that Tai Chi exercises are effective and reduce the fear of falling in older adults significantly. Thus, clinical guidelines, recommendations, a plan and audit tool have been created in our study to implement Tai Chi programs in clinics. The clinical guidelines for recommended intervention, the plan, and the audit tool recommend therapists to apply Tai Chi exercises with older adults with fear of falling, ambulatory ability, and no significant cognitive problems.

\section{Funding details}

No funding was required.

\section{Acknowledgement}

None.

\section{Conflict of interest}

Author declares that there is no conflict of interest..

\section{References}

1. Tinetti ME, Powell L (1993) Fear of falling and low self-efficacy: A cause of dependence in elderly persons. Journal of Gerontology 48: 35-38
2. Zhang J, Ishikawa Takata K, Yamazaku H, Morita T, Ohta T (2006) The effects of Tai Chi Chuan on physiological function and fear of falling in the less robust elderly: An intervention study for preventing falls. Archives of Gerontology and Geriatrics 42(2): 107-116.

3. Richardson WS, Wilson MC, Nishikawa J, Hayward RS (1995) The wellbuilt clinical question: A key to evidence-based decision. ACP Journal Club 123(3): A12-13.

4. Hughes I (2006) Action research in healthcare: what is the evidence? ALAR Journal 11(1): 29-39.

5. Li F, Harmer P, Fisher KJ, McAuley E, Chaumeton N, et al. (2005) Tai Chi and fall reductions in older adults: A randomized controlled trial. Journal of Gerontology 60(2): 187-194.

6. Sattin RW, Easley KA, Wolf SL, Chen Y, Kutner MH (2005) Reduction in fear of falling through intense Tai Chi exercise training in older, transitionally frail adults. Journal of the American Geriatrics Society 53(7): 1168-1178.

7. Wolf SL, Barnhart HX, Kutner NG, Mcneely M, Coogler C, et al. (2003) Selected as the best paper in the 1990s: Reducing frailty and falls in older persons: an investigation of Tai Chi and computerized balance training. Journal of the American Geriatrics Society 51(12): 1794-1803.
Creative Commons Attribution 4.0

International License

For possible submissions Click Here

\section{Submit Article}

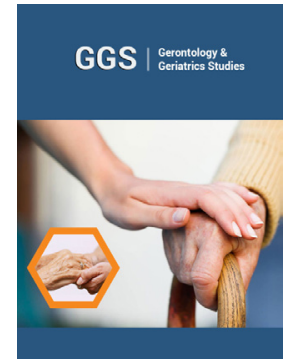

Gerontology \& Geriatrics Studies

\section{Benefits of Publishing with us}

- High-level peer review and editorial services

- Freely accessible online immediately upon publication

- Authors retain the copyright to their work

- Licensing it under a Creative Commons license

- Visibility through different online platforms 